\title{
MANAGEMENT OF EPIPHORA IN CHILDREN- PROSPECTIVE ANALYSIS
}

\author{
Balakrishnan $M^{1}$, Mohanraj $K^{2}$, Sowmiya K. R', Rekha $B^{4}$
}

${ }^{1}$ Associate Professor, Department of Ophthalmology, Sree Balaji Medical College and Hospital, Chormpet, Chennai. 2 Professor and HOD, Department of Ophthalmology, Sree Balaji Medical College and Hospital, Chormpet, Chennai. ${ }_{3}^{3}$ Associate Professor, Department of Community Medicine, Tagore Medical College. ${ }^{4}$ Senior Resident, Department of Ophthalmology, Sree Balaji Medical College and Hospital, Chormpet, Chennai. ABSTRACT

\section{BACKGROUND}

Lacrimation is caused by reflex over-production of tears from stimulation of the trigeminal nerve by irritation of the cornea or conjunctiva. In these cases, the excess watering is associated with symptoms of the underlying cause and treatment is usually medical. Obstructive epiphora is caused by mechanical obstruction of tear drainage. It is characterized by excessive watering which is exacerbated by a cold and windy atmosphere, and is least in a warm dry room. Most cases can be relieved by surgery. Lacrimal pump failure occurs secondary to lower lid laxity or weakness of the orbicularis muscle. Treatment is more difficult than that of obstructive epiphora.

Purpose- To study success of various methods of treatment for epiphora in children below 11 years and to compare clinical profile between children below 2 years (early onset) and children above 2 years (late onset).

Design- Prospective observational study.

\section{MATERIALS AND METHODS}

Study was conducted in 209 eyes of 167 patients ( 42 bilateral cases) during five years period between Jan 2010 to Jan 2015 . The success of treatment was defined as complete resolution of symptoms and negative regurgitation on pressure over lacrimal sac (ROPLAS) area; Patients were followed up for $8.4 \pm 2.1$ months.

\section{RESULTS}

87 percent ( 145 of 167) cases were below 2 years and 13 percent ( 22 of 167) were children above 2 years. The male: female ratio was 1.3:1. Seventy five percent cases were unilateral. Cause for $92 \%$ cases were congenital nasolacrimal duct obstruction (NLD0), $6 \%$ traumatic or surgical and $2 \%$ acquired NLDO. The success rate of total 209 cases were $98 \%$ (205 eyes), $89 \%$ for sac massage, $82 \%$ for probing, 64\% for external dacryocystorhinostomy (DCR). Statistically significant relation was noted between the treatment result and laterality (P-0.04), symptom severity (P-0.027), previously treated cases (P-0.024) and age. All cases below 2 years with NLDO were completely cured by sac massage and few cases with probing. No significant association was found between treatment result and sex (P-0.73).

\section{CONCLUSION}

Properly done sac massage alone for weeks to many months is best treatment for early onset NLDO in children less than 2 years. Probing was successful in $82 \%$ of children. Probing and DCR were required in older children. Mucoid discharge and recurrent ocular infection had decreased overall treatment success. There was significant correlation between laterality, symptom severity and previous treatment.]

\section{KEYWORDS}

Epiphora, Children, Observational Study, India.

HOW TO CITE THIS ARTICLE: Balakrishnan M, Mohanraj K, Sowmiya KR, et al. Management of epiphora in children- prospective analysis. J. Evolution Med. Dent. Sci. 2018;7(09):1091-1095, DOI: 10.14260/jemds/2018/248

\section{BACKGROUND}

Epiphora is excessive watering of eyes despite normal tear production due to any obstruction in lacrimal drainage pathway. Congenital nasolacrimal duct obstruction (CNLDO) is a common condition affecting $20 \%$ infants in their first year of life(1) and occurs due to the failure of canalization of nasolacrimal duct.(2)

'Financial or Other Competing Interest': None.

Submission 19-01-2018, Peer Review 12-02-2018,

Acceptance 18-02-2018, Published 26-02-2018.

Corresponding Author:

Sowmiya $K$. $R$,

2G, Quanta Trinity,

18 West CIT Nagar

Chennai-35.

E-mail: krs3012@gmail.com

DOI: $10.14260 /$ jemds $/ 2018 / 248$

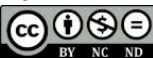

Spontaneous resolution occurs in the majority of cases by one year of life.(1,3) Treatment usually used to revert CNLDO are sac massage, probing, probing with intubation, balloon catheterization, silicon tube intubation and external dacryocystorhinostomy (DCR). Children till the age of one are typically treated with digital sac massage which has been reported to have high success rate (77-95\%).(3,4,5,6,7) Nasolacrimal duct probing is tried generally after the age of one year, $(4,5,6)$ and its success rate is $77 \%-97 \%$ after fresh application. There is controversy regarding the effectiveness of probing at early age of less than one year and at late age of more than 3 years. $(8,9)$ DCR is performed in CNLDO due to craniofacial anomalies, Down syndrome and in children with failed sac massage and probing. Acquired causes for epiphora are trauma, surgery, inflammation etc. leading to NLDO, canalicular obstruction or punctal stenosis and malposition. Various studies have evaluated the role of DCR in congenital 
as well as acquired cases of NLDO.(10,11,12) Our study covers a wide range of causes of epiphora and its treatment modalities for children. This study aims at evaluating clinical profile and success rates of sac massage, probing and DCR. Other objective was to find out difference in demographic and clinical characteristics between the early onset $(<2 \mathrm{yrs})$ and late onset ( $>2$ yrs) epiphora.

\section{MATERIALS AND METHODS}

Prospective observational study was performed on 209 eyes of 167 patients ( 42 bilateral cases) aged less than 11 years who presented with complaints of watering eyes to our department, which is a tertiary eye care centre in Chennai, India. Patients were selected from those who visited the department between Jan 2010 and Jan 2015. Some patients were referred by other nearby Ophthalmologists and general practitioners and after conducting medical camps. The study was conducted in the principles of declaration of Helsinki after getting permission from institutional Ethics Committee. Proper written and signed informed consent was obtained from parents or guardians. Procedures and surgeries were done by same surgeon. Epiphora was diagnosed based on any one of the following features - a history of watering and discharge for more than 4 weeks, presence of lacus lacrimalis, raised tear meniscus, discharge and regurgitation on pressure. Hyper lacrimation and pseudo epiphora cases and those not willing for follow up were excluded from this study.

CNLDO was diagnosed based on presenting symptoms like watering, discharge, swelling and redness noticed from birth or after birth. Acute dacryocystitis was diagnosed by the presence of acute onset swelling of lacrimal sac with pain redness and tenderness. Cases with history of many recurrences and remissions of pain and swelling were diagnosed as chronic dacryocystitis. Mucocele was defined as presence of asymptomatic swelling of the lacrimal sac area. Fistula was characterized by an abnormal opening around the sac area with or without discharge. Parents with a minimum follow up of 6.3 months from the day of presentation were included in this study. The following variables were recorded from patients' history and findings: Laterality, age at presentation, gender, presenting symptoms like watering, discharge, swelling, dacryocystitis, mucocele, pyocele, regurgitation on pressure, syringing in older children, treatment modality (sac massage, probing and DCR), duration of treatment, age at the time of probing or DCR and follow-up duration. In bilateral cases, each eye was considered as an independent case to avoid selection bias.

For all cases sac massage was started immediately as treatment. Syringing was done on each visit wherever possible in cooperative children under topical anesthesia. Broad spectrum antibiotic eye drops were instilled before and after massage. Oral antibiotic and anti-inflammatory drugs were given in infected cases. Massage was done 10 times every 3 hours by properly covering mouth and nose. Sac area and method was explained to the parents and demonstrated manually and through video on each visit based on Crigler's method.(13) Suitable finger and sufficient pressure was used considering the size of child. Broad spectrum antibiotic ointment was applied at night. Improper massage was the major reason for the failure of treatment for NLDO. Patients were advised to continue massage as a routine for 1 year even after recovery from NLDO. Respiratory infections were treated promptly after referring to physician and ENT specialist whenever required. Probing was considered when there was no relief even after continuous massage continued for 6 months. Probing or DCR without prior sac massage was considered in minority of patients presenting with acute dacryocystitis and pyocele after control of infection. All patients who failed to show recovery of CNLDO after a minimum of 3 months of sac massage trial were advised to undergo probing. Probing(14) and external DCR(15) were performed under general anesthesia. A repeated attempt to probe was made after 3 months after which DCR was advised.

Presenting symptom and signs, associated craniofacial and ocular anomalies, treatment given and any other investigation such as computerized tomography (CT) dacryocystography (DCG) were noted. The patients were followed up for a minimum period of 6.3 months after the treatment to look for the resolution of symptoms and signs. Treatment success was defined as the absence of fluid regurgitation on pressure at lacrimal sac (ROPLAS) and complete resolution of symptom for at least 6.1 months after a procedure or during the patient's last visit to the hospital whichever was later

\section{Statistical Analysis}

SPSS (Version 11) (SPSS Inc.; Chicago, USA) was used for analysis after collection of data. Descriptive statistics were used for demographic characteristics and the data being presented as percentages, mean and standard deviation. Chisquare and fishers exact test were used to test the difference in the two proportions. $\mathrm{P}<0.05$ was noted as statistically significant difference.

\section{RESULTS}

Totally 167 patients were studied. The mean age of onset of symptom was $1.3 \pm 3$ years (range -1 month to $10 \mathrm{yrs}$.). The mean age of consultation with doctor was $2.6 \pm 2.5$ yrs. (range- 1 month to 8 years). 145 patients (87\%) had an early onset ( $<2$ yrs. of age) and $22(13 \%)$ had late onset epiphora ( $>2$ yrs.). The male: female ratio in the early onset group was 1.2:1 and in late onset group was 1.4:1. Total 125 cases (75\%) were unilateral. Congenital NLDO was the most common cause of paediatric epiphora seen in $92 \%$ (154/167). Trauma (iatrogenic or non-iatrogenic) was the cause of $6 \%(10 / 167)$ paediatric NLDO. Acquired causes were the reason for $2 \%(3 / 167)$ cases of paediatric NLDO. Table- 1 shows the various types of injuries causing epiphora. Congenital NLDO was the cause for $99 \%$ of early onset group. But injuries and acquired causes were equal reasons for epiphora in late onset group.

\begin{tabular}{|c|c|}
\hline \multicolumn{2}{|c|}{$\mathbf{n}$} \\
\hline Type of injury & \\
\hline Road traffic accident & 4 \\
\hline Accidental fall from height & 1 \\
\hline Bow and arrow injury & 1 \\
\hline Gulli danda injury & 1 \\
\hline Cricket ball injury & 1 \\
\hline Post-surgical- after faciomaxillary surgery & 1 \\
\hline Cicatricial - post thermal injury & 1 \\
\hline Table 1. Distribution of cases with injury \\
\hline
\end{tabular}


Seventy five percent (125/167) cases first visited Ophthalmologist directly. Remaining cases first visited general practitioners and pediatricians directly and later referred to Ophthalmologist. Previous history of treatment was available in 80 cases $(57 \%$ in early onset group of eyes and $60 \%$ in late onset group) which included sac massage in 62 cases $(77 \%)$ and single trial of probing in 12 cases (15\%) and multiple trial in 5 cases $(6 \%)$ and 1 case $(1 \%)$ of failed DCR.

The commonest symptoms in all groups including early and late onset was discharge (68\%), watering (22\%), itching $(8 \%)$ and pain with swelling $(2 \%)$. We had also selected children with complaints of watering and who were associated with craniofacial and ocular anomalies. These ocular and systemic anomalies have been listed in table- 2 .

\begin{tabular}{|c|c|}
\hline & n \\
\hline Down's syndrome & 2 \\
\hline Craniosynostosis & 1 \\
\hline Apert syndrome & 1 \\
\hline Mild cranial anomalies & 1 \\
Total & $\mathbf{5}$ \\
\hline Other Ocular Anomalies & 6 \\
\hline Telecanthus & 1 \\
\hline Epiblepharon & 1 \\
\hline Iridofundal coloboma & 1 \\
\hline Lid coloboma & $\mathbf{9}$ \\
\hline Total & \\
\hline $\begin{array}{c}\text { Table 2. Distribution of ocular and, systemic and } \\
\text { craniofacial anomalies with epiphora }\end{array}$ \\
\hline
\end{tabular}

CT- Dacryocystography was used to locate obstruction in 3 cases out of 10 cases of traumatic childhood epiphora. Prior explanation was given to parents regarding safety and allergic reaction during the investigation. All 3 cases had obstruction at sac- NLD junction as evident by collection of dye in dilated lacrimal sac.

Different types of treatment modalities utilized include sac massage in all 209 eyes, (100\%), sac massage and probing in 22 eyes $(10 \%)$ and sac massage, probing and DCR in 11 eyes (5\%). Skin grafting was done along with DCR in a case of cicatricial NLD block after thermal injury. The treatment method given was based on the age of presentation as shown in Table-3. The mean duration of follow up was $8.4 \pm 2.1$ months.

\begin{tabular}{|c|c|c|c|}
\hline Age & Sac Massage (s) & S \& P & S, P \& DCR \\
\hline Upto 1 years & 140 & 0 & 0 \\
\hline 1-2 yrs & 7 & 3 & 0 \\
\hline 2-3 yrs & 0 & 3 & 0 \\
\hline 3-4 yrs & 0 & 2 & 0 \\
\hline 4-5 yrs & 0 & 2 & 0 \\
\hline 5-6 yrs & 0 & 2 & 0 \\
\hline 6-7 yrs & 0 & 2 & 0 \\
\hline 7-8 yrs & 0 & 2 & 1 \\
\hline 8-9 yrs & 0 & 1 & 1 \\
\hline 9-10 yrs & 0 & 1 & 2 \\
\hline 10-11 yrs & 0 & 0 & 3 \\
\hline Table 3. The type of successful treatment given based on \\
the age of presentation \\
\hline
\end{tabular}

P-Probing, DCR - Dacryocystorhinostomy
Total success rate of treatment was $98 \%$ (205/209) by various methods of treatment. Success rate of sac massage was $85 \%(187 / 209)$. Success rate of probing was $82 \%$ $(18 / 22)$ Success rate of external DCR was $64 \%$ (7/11). Few cases came back with recurrence of watering following initial success of treatment that included 22 eyes $(11 \%)$ of sac massage, $4(18 \%)$ eyes of probing and $4(36 \%)$ cases of external DCR. These cases were considered as failed treatment cases in respective treatment method. Only 4 eyes were declared as overall failed treatment at the end. We had advised these failed cases to undergo repeat DCR with intubation or dacryocystectomy (DCT). The success rate of DCR for NLDO (congenital and acquired) was higher (74\%) compared to traumatic eyes (54\%). The relation between treatment result with some demographic factors was studied. They included age, sex, laterality, aetiology, symptom severity, and previous treatment history. Increasing age was a significant risk factor related with the failure of sac massage and probing. The success rate of sac massage and probing declined after 2 years of age $(\mathrm{P}<0.05)$. Statistically significant association was seen between treatment result and laterality (P-0.04), symptom severity (P-0.027) and previous treatment history ( $\mathrm{P}-0.024)$ (Table -4$)$. The success rate of probing in eyes undergoing a first-time treatment of syringing and probing was $90 \%(40 / 44)$, but the success rate in eyes with a previous failed syringing and probing was $57 \%(17 / 30)$ $(\mathrm{P}<0.05)$.

\begin{tabular}{|c|c|c|}
\hline & Success & Failure \\
\hline \multicolumn{3}{|c|}{ Laterality (P-0.04) } \\
\hline Unilateral & 108 & 16 \\
\hline Bilateral & 31 & 11 \\
\hline \multicolumn{3}{|c|}{$\begin{array}{l}\text { Symptom severity } \\
\text { (P-0.027) }\end{array}$} \\
\hline Watering & 63 & 7 \\
\hline Discharge & 104 & 34 \\
\hline \multicolumn{3}{|c|}{ Previous treatment history (P-0.024) } \\
\hline present & 106 & 34 \\
\hline absent & 61 & 7 \\
\hline \multicolumn{3}{|c|}{$\begin{array}{l}\text { Table 4. Treatment results based on laterality, symptom } \\
\text { severity and previous treatment history }\end{array}$} \\
\hline
\end{tabular}

\section{DISCUSSION}

Epiphora is a common problem in children. Many cases are yet to be explored other than CNLDO. We conducted prospective evaluation of pediatric patients with watering due to all reasons and compared the data between the early versus and late onset group. We analysed a large cohort of children with CNLDO and with wide range of age groups and were treated with sac massage, probing and external DCR either solitarily or sequentially.

Congenital NLDO was the commonest cause in our study followed by post traumatic NLDO. Ninety-nine percent cases below 1 year were due to congenital NLDO. In late onset cases both congenital and acquired cases were almost equally prevalent. Commonest cause of trauma was due to road traffic accident which resulted in medial canthus and sac area injuries. These were mostly avulsion injuries typically associated with a triad of telecanthus, epiphora and ptosis as also reported by Priel et al.(16) The location of the site of obstruction before treatment is important in traumatic cases. 
CT -DCG is a useful diagnostic tool in clinically challenging cases of traumatic epiphora. It helps to (1) find out the level of obstruction;(2) note whether the obstruction is complete or incomplete, intrinsic or extrinsic to the duct and (3) find out the cause of obstruction,(17). CT-DCG was done in posttraumatic cases and revealed that the commonest site of obstruction was sac-NLDO junction.

There was greater symptom severity in late onset group with $77 \%$ cases presenting discharge, $19 \%$ with watering and $4 \%$ eyes with lacrimal sac area swelling. This may be explained by the prolonged inflammation leading to greater symptoms and signs. The results of probing with or without silastic intubation reported in other studies range from 55\% to $96 \% .(18,19,20,21,22,23,24)$ The success rate of probing in our study was $82 \%$. This lower rate may be due to inclusion of some complicated cases like previously failed cases and associated with craniofacial anomalies. Additional procedures like inferior turbinate fracture repair, intubation DCR, endoscopic DCR, Silastic intubation were not done in this study cases.

All patients decided for external DCR underwent DCR without intubation and without endoscopy. These factors might be the cause for less success rate for DCR (64\%) on comparing with other studies $(25,26)$. Even though less number of DCR done in our study, post traumatic DCR cases had less success rate than non-traumatic cases which was almost equal to other studies.(10,12) There was higher success rate in early onset groups (88\%) than in late onset group (73\%)

There was statistically significant association between treatment result and laterality (P-0.04), symptom severity ( $\mathrm{P}$ 0.027 ) and previous treatment history (P-0.024). Honavar etal reported reasons predictive of failure of probing such as age > 36 months, bilateral affection, failed conservative therapy, failed earlier probing, dilated lacrimal sac, and firm obstruction.(20) Mannor etal found a significant association between success of probing with age and symptom severity but not with a previous treatment history(27) but Kashkouli et al found no association with laterality or presence of infection.(23) Repka etal found an association with laterality and symptom severity.(19)

NLDO which is common in first year of life resolve spontaneously or after sac massage.(28) In unresolved cases, probing is used in most cases. Success rate was decreasing on increasing age. Several studies have found a significant increase in the failure rate in those patients undergoing probing after the age of 12 months. $(27,20,23,29,30)$ Table 5 shows the success rate of probing reported in several studies. Resolution of symptoms can also be attributed to spontaneous resolution in children less than one year. It is not possible to differentiate whether the success in this age group was due to spontaneous resolution or solely due to intervention in the absence of control group.

\begin{tabular}{|c|c|c|c|c|}
\hline \multirow[t]{2}{*}{ Study } & \multirow[t]{2}{*}{ Number of Eyes } & \multicolumn{3}{|c|}{ Success Rate of Simple Probing as per the Age } \\
\hline & & 0-12 months & 13-24 months & >24 months \\
\hline Katowitz and Welsh(30) & 572 & $97 \%$ & $69 \%$ & $33.3 \%$ \\
\hline Zwaan(31) & 110 & $97 \%$ & $88 \%$ & $92 \%$ \\
\hline Robb(22) & 280 & \multicolumn{3}{|c|}{$98 \%$ from 0 to 24 months } \\
\hline Mannor et al(27) & 142 & $92 \%$ & $89 \%$ & $69 \%$ \\
\hline Honavar et al(20) & 60 & \multicolumn{3}{|c|}{ All patients $>24$ months age } \\
\hline Maheswari(21) & 84 & $88.1 \%$ & & $80.1 \%$ \\
\hline Kashkouli et al(29) & 207 & $92 \%$ & $85 \%$ & $65 \%$ \\
\hline Repka et al(19) & 955 & $78 \%$ & $79 \%$ & $79 \%$ \\
\hline Lee et al(24) & \multicolumn{4}{|c|}{ Overall success rate of $86 \%$ (average age of 12.4 months) } \\
\hline Present study & Number of eyes & 12-23 months & 24-35 months & $\geq 36$ months \\
\hline Balakrishnan et al & 22 & $100 \%$ & $100 \%$ & $40 \%$ \\
\hline
\end{tabular}

The strength of our study is the heterogeneity in patient population giving a chance to evaluate various factors associated with treatment results. Many factors such as variable follow up, low socio-economic status, low literacy rate, infection status, minor anatomical variation could not be analysed which could have changed the outcome. Other lapses are non-utilization of all objective tests for lacrimal patency and various other treatment modalities.

\section{CONCLUSION}

Sac massage and probing is successful in CNLD in majority of cases in our study and its success declines with a progressive increase in age. Sac massage as a primary treatment prior to probing may be successful in some older children as well and, as it does not negatively impact outcome if probing is worth a try. Traumatic and other secondary causes contribute significantly to the aetiology of the older age group. Treatment failures are related to age, increasing symptom severity and previous history of treatment.

\section{REFERENCES}

[1] MacEwen CJ, Young JD. Epiphora during the first year of life. Eye (Lond) 1991;(5 Pt 5):596-600.

[2] Hughes RK, FitzGerald DE. Congenital Nasolacrimal duct obstruction: an opotmetric perspective. J Behav Optom 2000;11(4):94-6.

[3] Nelson LR, Calhoun JH, Menduke H. Medical management of congenital Nasolacrimal duct obstruction. Ophthalmology 1985;92(9):1187-90.

[4] Baker JD. Treatment of congenital Nasolacrimal system obstruction. J Pediatr Ophthalmol Strabismus 1985;22:34-6.

[5] Casady DR, Meyer DR, Simon JW, et al. Stepwise treatment paradigm for congenital nasolacrimal duct obstruction. Ophthal Plast Reconstr Surg 2006;22(4):243-7.

[6] Katowitz JA, Welsh MG. Timing of initial probing and irrigation in congenital Nasolacrimal duct obstruction. Ophthalmology 1987;94(6):698-705. 
[7] Stager D, Baker JD, Frey T, et al. Office probing of congenital nasolacrimal duct obstruction. Ophthalmic Surg 1992;23(7):482-4.

[8] Petersen RA, Robb RM. The natural course of congenital obstruction of the nasolacrimal duct. J Pediatr Ophthalmol Strabismus 1978;15(4):246-50.

[9] Ffooks 00. Dacryocystitis in infancy. Br J Ophthalmol 1962;46(7):422-34.

[10] Barnes EA, Abou-Rayyah Y, Rose GE. Pediatric dacryocystorhinostomy for nasolacrimal duct obstruction. Ophthalmology 2001;108(9):1562-4.

[11] Marr JE, Drake-Lee A, Willshaw HE. Management of childhood epiphora. $\mathrm{Br} \quad \mathrm{J}$ Ophthalmol 2005;89(9):1123-6.

[12] Nemet AY, Fung A, Martin PA, et al. Lacrimal drainage obstruction and dacryocystorhinostomy in children. Eye (Lond) 2008;22(7):918-24.

[13] Crigler LW. The treatment of congenital dacryocystitis. J Am Med Assoc 1923;81(1):23-4.

[14] Robb RM. Congenital nasolacrimal duct obstruction. Ophthalmol Clin North Am 2001;14(3):443-6, viii.

[15] Hakin KN, Sullivan TJ, Sharma A, et al. Paediatric dacryocystorhinostomy. Aust Z J Ophthalmol 1994;22(4):231-5.

[16] Priel A, Leelapatranurak K, OH SR, et al. Medial canthal degloving injuries: the triad of telecanthus, ptosis, and lacrimal trauma. Plast Reconstr Surg 2011;128(4):300e-5e.

[17] Udhay P, Noronha OV, Mohan RE. Helical computed tomographic dacryocystography and its role in the diagnosis and management of lacrimol drainage system blocks and medical canthal masses. Indian J Ophthalmol 2008;56(1):31-7.

[18] Engel JM, Hichie-Schmidt C, Khammar A, et al. Monocanalicular silastic intubation for the initial correction of congenital nasolacrimal duct obstruction. J AAPOS 2007;11(2):183-6.

[19] Pediatric Eye Disease Investigator Group, Repka MX, Chandler DL, et al. Primary treatment of nasolacrimal duct bstruction with probing in children younger than 4 years. Ophthalmology 2008;115(3):577-84.e3.
[20] Honavar SG, Prakash VE, Rao GN. Outcome of probing for congenital nasolacrimal duct obstruction in older children. AM J Ophthlmol 2000;130(1):42-8.

[21] Maheshwari R. Results of probing for congenital nasolacrimal duct obstruction in children older than 13 months of age. Indian J Ophthalmol 2005;53(1):4951.

[22] Robb RM. Success rates of nasolacrimal duct probing at time intervals after 1 year of age. Ophthalmology 1998;105(7):1307-10.

[23] Kashkouli MB, Beigi B, Parvaresh MM, et al. Late and very late initial probing for congenitial nasolacrimal duct obstruction: What is the cause of failure? $\mathrm{Br} \mathrm{J}$ Ophthalmol 2003;87(9):1151-3.

[24] Lee DH, Fudemberg SJ, Davitt BV, et al. Success of simple probing and irrigation in patients with nasolacrimal duct obstruction and otitis media. J AAPOS 2005;9(2):192-4.

[25] Hakin KN, Sullivan TJ, Sharma A, et al. Paediatric dacryocystorhinostomy. Aust N Z J Ophthalmol 1994;22(4):231-5.

[26] Nowinski TS, Flanagan JC, Mauriello J. Pediatric dacryocystorhinostomy. Arch Ophthalmol 1985;103(8):1226-8.

[27] Mannor GE, Rose GE, Frimpong-Ansah K, et al. Factors affecting the success of nasolacrimal duct probing for congenital nasolacrimal duct obstruction. AM J Ophthalmol 1999;127(5):616-7.

[28] Paul TO, Shepherd R. Congenital nasolacrimal duct obstruction: Natural history and the timing of optimal intervention. J Pediatr Ophthalmol Strsbismus 1994;31(6):362-7.

[29] Kashkouli MB, Kassaee A, Tabatabaee Z. Initial nasolacrimal duct probing in children under age 5: cure rate and factors affecting success. J AAPOS 2002;6(6):360-3.

[30] Katowitz JA, Welsh MG. Timing of initial probing and irrigation in congenital nasolacrimal duct obstruction. Ophthalmology 1987;94(6):698-705.

[31] Zwaan J. Treatment of congenital Nasolacrimal duct obstruction before and after the age of 1 year. Ophthalmic Surg Lasers 1997;28(11):932-6. 